\title{
EFEITO DE DOIS SISTEMAS DE MANEJO DO SOLO NAS PROPRIEDADES FÍSICO- HÍDRICAS, DESENVOLVIMENTO RADICULAR E PRODUTIVIDADE DO MILHO IRRIGADO
}

\section{MARCELO AUGUSTO DE AGUIAR E SILVA ${ }^{1}$; LEONARDO PRETTO DE AZEVEDO ${ }^{2}$; JOÃO CARLOS CURY SAAD ${ }^{3}$ E ROGER NABEYAMA MICHELS ${ }^{4}$}

\author{
${ }^{1}$ Centro de Ciências Agrárias, Departamento de Agronomia, Universidade Estadual de Londrina, Londrina, PR, \\ aguiaresilva@uel.br \\ ${ }^{2}$ Instituto Federal de Educação, Ciência e Tecnologia de São Paulo, Campus São Roque. Rod. Prefeito Quintino de \\ Lima 2100, São Roque, SP, pretto@ifsp.edu.br \\ ${ }^{3}$ Departamento de Engenharia Rural, Faculdade de Ciências Agronômicas, Universidade Estadual Paulista, Botucatu, \\ SP, joaosaad@fca.unesp.br \\ ${ }^{4}$ Universidade Tecnológica Federal do Paraná, Campus Apucarana. Rua Marcílio Dias, 635, Apucarana, PR, \\ rogernmichels@utfpr.edu.br
}

\section{RESUMO}

A cultura do milho faz parte da rotação de culturas praticadas pelos irrigantes do sudoeste paulista, os quais utilizam o plantio direto como forma de uso sustentável do solo. O efeito dessa prática conservacionista sobre as propriedades físico-hídricas do solo, o desenvolvimento radicular e a produtividade da cultura do milho, comparativamente com o preparo convencional, foi o objetivo desse trabalho. O experimento foi conduzido na Fazenda Buriti-Mirim, município de Angatuba, SP (2330'13" S, 48 35'37" W; 640m), durante o segundo semestre de 2003, utilizando uma área de Argissolo Acinzentado irrigada por pivô central, dividida em dois tipos de manejo do solo: preparo convencional e plantio direto. Embora no plantio direto tenha-se encontrado maior densidade do solo e menor quantidade de água disponível, os dois manejos não diferiram significativamente para resistência do solo à penetração, desenvolvimento radicular e produtividade do milho. Nos dois sistemas de manejo, $90 \%$ das raízes se concentraram nos primeiros $20 \mathrm{~cm}$ de profundidade.

Palavras-chave: plantio direto, raiz, água disponível, resistência do solo à penetração.

AgUIAR E SILVA, M. A.; AZEVEDO, L. P.; SAAD, J. C. C.; MICHELS, R. N.

\section{EFFECT OF TWO SOIL MANAGEMENT SYSTEMS ON PHYSICAL AND HYDRICAL PROPERTIES, ROOT DEVELOPMENT AND YIELD OF IRRIGATED CORN}

\section{ABSTRACT}

Corn cultivation is part of crop rotation used by irrigation farmers from the southwestern region of São Paulo state, Brazil, who use no-tillage soil management as a kind of sustainable use of 
soil. The effect of this conservative practice on physical and hydrical properties of the soil, root development and corn crop yield compared to the conventional management was the objective of this work. The experiment was held at the Buriti-Mirim Farm, Angatuba, SP, Brazil, using an irrigated area with a center pivot system and two types of soil management: conventional and no-tillage systems. Although the no-tillage management had higher soil density and less water availability, no significant difference was found for both management systems concerning soil resistance to penetration, root development and crop yield. In both systems of soil management, $90 \%$ of roots were concentrated in the first $0-20 \mathrm{~cm}$ of soil layer.

Keywords: root, soil resistance to penetration, water availability, no-tillage management.

\section{INTRODUÇÃO}

Com a crescente preocupação de pesquisadores e agricultores na busca por elevada produtividade aliada à preservação dos recursos naturais, principalmente água e solo, fazem-se necessários estudos que avaliem diferentes sistemas de manejo do solo.

Na região do Alto Paranapanema o tráfego contínuo de equipamentos pesados e o preparo intensivo dos solos, em áreas irrigadas, tem sido motivo de preocupação, pois pode levar a compactação de camadas do solo e, conseqüentemente, reduzir a produtividade das culturas.

Uma alternativa para evitar tais efeitos indesejáveis é o plantio direto, entretanto, nos primeiro anos de implantação desse manejo as camadas superficiais do perfil do solo, quando comparadas ao preparo convencional, geralmente apresentam maiores valores de densidade do solo (Cunha et al., 2011; Reinert et al., 2008; Bergamin et al. 2010; Bescansa et al., 2006; Moret \& Arrúe, 2007). Isto se deve, principalmente, ao não revolvimento do solo e a pressão exercida pelo trânsito de máquinas e implementos agrícolas (Pires et al., 2011; Bergamin et al., 2010; Silveira Neto et al., 2006), o que afeta a retenção de água no mesmo (Bescansa et al., 2006).

Vários trabalhos mostram que o solo sob plantio direto retém mais água (Castro et al., 2010; Bescansa et al., 2006; Vita et al., 2007; Dalmago et al., 2009), entretanto, Shukla et al. (2003) observaram que o preparo convencional foi o que apresentou retenção de água mais elevada. Por outro lado, Bortoluzzi et al. (2008), Silva et al. (2005) e Costa et al. (2006) não encontraram diferenças de armazenamento de água entre os sistemas de manejo, plantio direto e preparo convencional.

A quantidade de água no solo é o principal fator que afeta a taxa de crescimento das raízes do milho (Barber et al., 1988), sendo que, normalmente, sua profundidade efetiva varia de 40 a $50 \mathrm{~cm}$ (Albuquerque \& Resende, 2002).

Um dos atributos físicos do solo que pode restringir ou mesmo impedir o desenvolvimento das raízes do milho é a resistência do solo à penetração (RSP). De maneira geral, solos sob plantio direto apresentam maiores valores de RSP em relação aos solos sob preparo convencional (Silva et al., 2005). Tavares Filho et al. (2001) mostraram que valores de RSP superiores a 3,50 MPa, não restringiram o desenvolvimento radicular do milho. De acordo com Freddi et al. (2006), RSP variando de 0,90 a 2,00 MPa não restringiram a produtividade da cultura do milho.

Os resultados referentes aos diferentes manejos de solo influenciando a produtividade do milho são contraditórios. Comparando-se o sistema plantio direto e preparo convencional, foi 
observado aumento do rendimento de grãos de milho sob plantio direto por Marques et al. (2010) enquanto outros autores encontraram rendimentos inferiores (Lopes et al., 2009; Hill, 1990; Sonae \& Ball, 1998) neste sistema de manejo. Para Carvalho et al. (2004) e Berolini et al. (2006) os sistemas de manejo do solo não influenciaram os componentes de produção da cultura de milho.

No sudoeste do Estado de São Paulo, na bacia Hidrográfica do Alto Paranapanema, há uma grande área de culturas anuais, basicamente cereais, irrigados por pivô central, na qual o plantio direto é adotado como forma de uso sustentável do solo e da água. Entretanto, as mudanças estruturais no solo e, conseqüentemente, as alterações promovidas por este manejo nas propriedades físico-hídricas do solo e no desenvolvimento radicular das culturas ainda não foram quantificadas.

Desta forma, o objetivo desse trabalho foi avaliar como dois diferentes sistemas de manejo, utilizados pelos agricultores irrigantes do sudoeste paulista, interferem na quantidade de água disponível, na compactação do solo, no desenvolvimento radicular e na produtividade do milho, irrigado via pivô central.

\section{MATERIAL E MÉTODOS}

$\mathrm{O}$ experimento foi instalado e conduzido numa área de Argissolo Acinzentado (Embrapa 2006) de 35 ha irrigada via pivô central na Fazenda Buriti-Mirim, município de Angatuba, SP (latitude 23030'13" S, longitude 48 35'37" W; altitude média de 640m), durante o segundo semestre de 2003. A cultura utilizada foi o milho (Zea mays L.), híbrido DKB 215, cuja semeadura ocorreu em 15 de agosto de 2003 e a colheita dia 15 de janeiro de 2004, totalizando 154 dias de ciclo da cultura.

O delineamento experimental utilizado foi o inteiramente casualizado com dois tratamentos: plantio direto e preparo convencional, com 13 parcelas cada. As médias dos resultados obtidos foram comparadas pelo teste $t$ de Student a $5 \%$ de probabilidade.

O preparo convencional foi realizado mediante o uso de arado e grade, sendo realizada uma única passagem de cada implemento, enquanto o plantio direto caracterizou-se pela semeadura realizada sob os restos da cultura anterior, sem revolvimento do solo. Utilizou-se a denominação plantio direto, entretanto a parcela sem revolvimento não caracteriza um sistema de plantio direto contínuo, uma vez que, periodicamente são realizadas operações de preparo do solo para eliminação da soqueira do algodão e subsolagem para eliminação das camadas compactadas e redistribuição dos nutrientes no perfil do solo (Tabela 1).

Tabela 1. Rotação de culturas segundo a programação de plantio.

\begin{tabular}{cccccc}
\hline \multicolumn{2}{c}{2001} & \multicolumn{2}{c}{2002} & \multicolumn{2}{c}{2003} \\
\hline $1^{\circ}$ semestre & $2^{\circ}$ semestre & $1^{\circ}$ semestre & $2^{\circ}$ semestre & $1^{\circ}$ semestre & $2^{\circ}$ semestre \\
\hline Feijão & Milho & Feijão & Algodão & Trigo & Milho \\
\hline
\end{tabular}

Antes da instalação do experimento foram coletadas amostras não deformadas de solo com o auxílio de anéis volumétricos, nas camadas de 0-0,05 m, 0,05-0,10 m, 0,10-0,20 m e 0,20- 
0,40 m, nas duas condições de manejo do solo, para obtenção de sua curva característica de retenção de água e a realização da análise física do solo. As amostras foram encaminhadas para os Laboratórios de Física dos Solos do Departamento de Recursos Naturais, da Faculdade de Ciências Agronômicas, UNESP, Botucatu. Visando caracterizar a retenção de água do solo, com valores correspondentes em potencial de água no solo, efetuou-se a determinação da curva característica de retenção de água. Utilizou-se o programa computacional Soil Water Retention Curve - SWRC (Dourado Neto et al., 1990) para ajustar matematicamente os dados ao modelo não linear proposto por Van Genuchten (1980).

Para a determinação da resistência mecânica do solo à penetração, foi utilizado um penetrômetro hidráulico-eletrônico, de acordo com Lanças \& Santos Filho (1998). O penetrômetro hidráulico-eletrônico, montado sobre uma carreta para transporte rodoviário e aplicação em tratores com sistema hidráulico, apresenta um cone com área da base de $320 \mathrm{~mm}^{2}$, ângulo sólido de $30^{\circ}$ e velocidade constante de penetração no solo de $30 \mathrm{~mm} \mathrm{~s}^{-1}$ conforme ASAE S313.2 (1991). O sistema eletrônico possui um sistema de aquisição de dados (Microlloger 23X, Campbell), sensor de força (célula de carga de $10000 \mathrm{~N}$ ) e sensor de profundidade (potenciômetro rotativo). As profundidades para determinação do índice de cone foram de 0 0,$05 ; 0,05-0,10 ; 0,10-0,20 ;$ e $0,20-0,40 \mathrm{~m}$, na condição de preparo convencional e plantio direto.

O desenvolvimento radicular foi avaliado quando $50 \%$ das plantas encontravam-se em pleno florescimento, e sua amostragem foi realizada utilizando-se um trado de aço galvanizado com diâmetro de $4,5 \mathrm{~cm}$. A coleta de solo para a análise de raízes ocorreu nos dias 24 e 25 de novembro de 2003, em cinco camadas $(0-0,05 ; 0,05-0,10 ; 0,10-0,20 ; 0,20-0,40$ e $0,40-0,60 \mathrm{~m})$. As amostras foram retiradas na linha de plantio, entre uma planta e outra, com quatro repetições por parcela, totalizando 52 amostras de cada camada por tratamento. Posteriormente, as raízes foram separadas do solo por lavagem em água corrente, com auxílio de uma peneira de $0,5 \mathrm{~mm}$. As amostras de raízes depois de lavadas e separadas, foram acondicionadas em coletores universais com uma solução de álcool $70 \%$ e levadas à geladeira a uma temperatura de $4^{\circ} \mathrm{C}$.

As variáveis que caracterizam o desenvolvimento radicular foram determinadas em um Scanner acoplado a um computador dotado do Software WinRhizo, que utiliza como princípio o método proposto por Tennant (1975). Nesse equipamento determinou-se o comprimento $\left(\mathrm{Km} \mathrm{m}^{-3}\right)$, a superfície $\left(\mathrm{m}^{2} \mathrm{~m}^{-3}\right)$ e o diâmetro radicular $(\mathrm{cm})$. Após essas avaliações as amostras foram secas em estufa a $65^{\circ} \mathrm{C}$, até atingirem peso constante, para a determinação da produção de matéria seca radicular $\left(\mathrm{g} \mathrm{m}^{-3}\right)$.

Por ocasião da colheita da cultura do milho foram coletadas 10 plantas seqüenciais em local pré-determinado na área útil de cada parcela, totalizando 130 amostras por tratamento. Essas plantas foram levadas para laboratório para determinação de: número de espigas por planta, número de grãos por espiga e massa de 1000 grãos $(\mathrm{g})$ por parcela.

\section{RESULTADOS E DISCUSSÕES}

No plantio direto, onde periodicamente ocorreram operações de preparo do solo, a densidade do solo apresentou valores superiores aos encontrados no preparo convencional para as camadas avaliadas (Tabela 2), corroborando com Bescansa et al. (2006); Moret \& Arrúe (2007); Reinert (2008); Bergamin et al. (2010); Cunha (2011); Aguiar \& Silva et al. (2012). O não revolvimento contínuo do solo e a movimentação de máquinas e implementos agrícolas 
aumentaram sua densidade (Cunha et al., 2011; Bergamin et al., 2010; Silveira Neto et al., 2006). Entretanto, os valores de densidade entre os tratamentos foram muito próximos, principalmente nas camadas mais superficiais, que não caracterizou o efeito do manejo do solo sobre essa variável.

Tabela 2. Umidades correspondentes à capacidade de campo (CC), ponto de murcha permanente (PMP), água disponível (AD), densidade (Ds) e textura em diferentes camadas de solo para os manejos, preparo convencional (PC) e plantio direto (PD).

\begin{tabular}{ccccccc}
\hline $\begin{array}{c}\text { Manejo } \\
\text { de solo }\end{array}$ & $\begin{array}{c}\text { Camada } \\
(\mathrm{m})\end{array}$ & $\begin{array}{c}\mathrm{CC} \\
\left(\mathrm{cm}^{3} \mathrm{~cm}^{-3}\right)\end{array}$ & $\begin{array}{c}\text { PMP } \\
\left(\mathrm{cm}^{3} \mathrm{~cm}^{-3}\right)\end{array}$ & $\begin{array}{c}\mathrm{AD} \\
\left(\mathrm{mm} \mathrm{cm}^{-}\right. \\
1)\end{array}$ & $\begin{array}{c}\text { Ds } \\
\left(\mathrm{g} \mathrm{cm}^{-3}\right)\end{array}$ & Textura \\
\hline \multirow{3}{*}{ PC } & $0-0,05$ & 0,1756 & 0,0436 & 1,32 & 1,64 & Média \\
& $0,05-0,10$ & 0,1625 & 0,0470 & 1,16 & 1,65 & Média \\
& $0,10-0,20$ & 0,1517 & 0,0337 & 1,18 & 1,59 & Média \\
& $0,20-0,40$ & 0,1294 & 0,0216 & 1,08 & 1,53 & Média \\
\hline \multirow{3}{*}{ PD } & $0-0,05$ & 0,1807 & 0,0824 & 0,98 & 1,65 & Arenosa \\
& $0,05-0,10$ & 0,1891 & 0,0934 & 0,96 & 1,67 & Média \\
& $0,10-0,20$ & 0,1849 & 0,0839 & 1,01 & 1,69 & Arenosa \\
& $0,20-0,40$ & 0,1948 & 0,1068 & 0,88 & 1,55 & Arenosa \\
\hline
\end{tabular}

Os diferentes sistemas de manejo influenciaram as propriedades físico-hídricas do solo, sendo que o plantio direto apresentou, para todas as camadas avaliadas, menor quantidade de água disponível, contrariando Bescansa et al. (2006); Vita et al. (2007); Dalmago et al. (2009); Castro (2010) e concordando com Shukla et al. (2003). Como periodicamente houve revolvimento do solo, e sendo o efeito dos sistemas de manejos alterando as características físicohídricas do solo dependente, entre outros fatores, do tempo de uso (Costa et al., 2003), este talvez tenha sido insuficiente para promover no plantio direto mudanças estruturais no solo, e conseqüentemente, aumentar a quantidade de água armazenada e disponível às plantas, mostrando que os sistemas de manejo adaptam-se diferentemente a cada região e a sua condição edafoclimática particular.

Utilizando-se a resistência do solo à penetração (RSP) para determinar a compactação do solo, os valores não diferiram significativamente (Tabela 3), discordando de Silva et al., (2005) e de Aguiar \& Silva et al. (2012) . Esses valores estão relacionados à técnica de preparo do solo, onde as ferramentas utilizadas acabaram por transferir seu peso ao subsolo, na profundidade média de trabalho. As camadas de 0,05 a 0,10 e 0,10 a $0,20 \mathrm{~m}$ apresentaram os maiores valores de RSP, evidenciando alteração na profundidade do "pé de grade ou pé de arado", devido a problemas na regulagem da profundidade efetiva de trabalho. O mesmo efeito também foi observado no plantio direto, pois, periodicamente, ocorreram operações de preparo do solo neste manejo. Porém não se verifica indicação de restrição ao desenvolvimento radicular em nenhuma situação, pois, conforme Tavares Filho et al. (2001), os valores de RSP superiores a 3,50MPa não restringiram o desenvolvimento radicular do milho (Tabela 4). 
Tabela 3. Valores de resistência do solo à penetração $(\mathrm{MPa})$ e teor de água das amostras no momento da coleta de dados, para as condições de plantio direto (PD) e preparo convencional (PC) nas diferentes camadas de solo avaliadas

\begin{tabular}{ccccc}
\hline $\begin{array}{c}\text { Camada } \\
(\mathrm{m})\end{array}$ & PD & PC $(\mathrm{MPa})$ & \multicolumn{2}{c}{ Teor de água das amostras (\%) } \\
\hline $0-0,05$ & $0,902 \mathrm{a}$ & $0,930 \mathrm{a}$ & 16,51 & PC \\
$0,05-0,10$ & $0,206 \mathrm{a}$ & $0,214 \mathrm{a}$ & 19,25 & 20,77 \\
$0,10-0,20$ & $0,186 \mathrm{a}$ & $0,224 \mathrm{a}$ & 17,93 & 18,40 \\
$0,20-0,40$ & $0,158 \mathrm{a}$ & $0,170 \mathrm{a}$ & 12,73 & 13,37 \\
\hline
\end{tabular}

Médias seguidas de letras iguais na coluna não diferem estatisticamente entre si pelo teste $t$ de Student a 5\% de probabilidade.

Nota-se na Tabela 4 que, em ambos os tratamentos, 90\% do comprimento radicular se concentraram nos primeiros $0,20 \mathrm{~m}$ de profundidade, discordando dos valores obtidos por Albuquerque \& Resende (2002). Possivelmente, o sistema radicular mais superficial, nos dois manejos, esteja relacionado à irrigação e a precipitação, que mantiveram estas camadas com elevado conteúdo hídrico, fazendo com que as raízes não precisassem explorar camadas mais profundas de solo. Porém, na camada de 0 a $0,05 \mathrm{~m}$, o plantio direto concentrou $24 \%$ do comprimento total de raízes, enquanto o preparo convencional, $41 \%$. Isto se deve, basicamente, ao maior valor de água disponível apresentado pelo preparo convencional nesta camada (Tabela 2), uma vez que a densidade e a RSP foram semelhantes aos registrados no plantio direto.

Tabela 4. Distribuição do comprimento radicular do milho no perfil do solo, nas condições de plantio direto e preparo convencional, para as camadas avaliadas.

\begin{tabular}{ccc}
\hline Camada $(\mathrm{m})$ & Plantio direto & Preparo convencional \\
\hline $0-0,05$ & $24 \%$ & $41 \%$ \\
$0,05-0,10$ & $40 \%$ & $34 \%$ \\
$0,10-0,20$ & $26 \%$ & $15 \%$ \\
$0,20-0,40$ & $7 \%$ & $7 \%$ \\
$0,40-0,60$ & $3 \%$ & $3 \%$ \\
\hline
\end{tabular}

A camada de 0 a $0,05 \mathrm{~m}$ também apresentou diferença significativa no peso seco de raízes (Tabela 5), para as outras variáveis de desenvolvimento radicular não houve diferença significativa entre os tratamentos. 
Tabela 5. Comprimento $\left(\mathrm{km} \mathrm{m}^{-3}\right)$, superfície $\left(\mathrm{m}^{2} \mathrm{~m}^{-3}\right)$, peso seco $\left(\mathrm{g} \mathrm{m}^{-3}\right)$ e diâmetro $(\mathrm{cm})$ radicular do milho no plantio direto (PD) e preparo convencional (PC) nas diferentes camadas avaliadas.

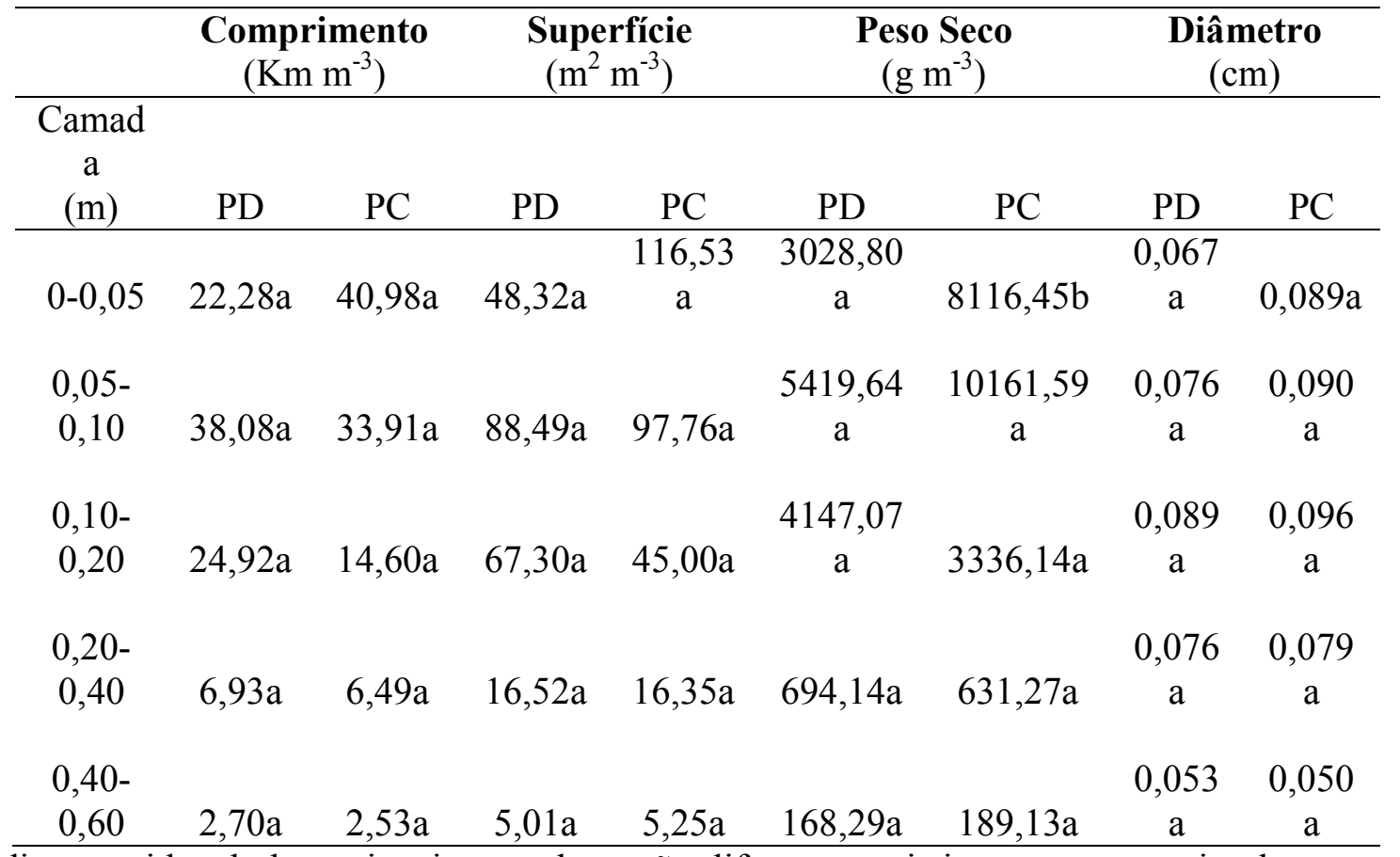

Médias seguidas de letras iguais na coluna não diferem estatisticamente entre si pelo teste $\mathrm{t}$ de Student a $5 \%$ de probabilidade.

Como os componentes avaliados de desenvolvimento radicular praticamente não diferiram, não houve diferença significativa entre a produtividade e os demais componentes da produção do milho para os manejos (Tabela 6). Estes resultados assemelham-se aos obtidos por Carvalho et al. (2004) e Berolini et al. (2006) que também não encontraram diferenças na produtividade do milho cultivado em diferentes sistemas de manejos.

Tabela 6. Número de espigas por planta, número de grãos por espiga, massa de 1000 grãos e produtividade do milho em razão de diferentes preparos de solo, preparo convencional e plantio direto.

\begin{tabular}{ccccc}
\hline Manejo de solo & $\begin{array}{c}\text { Número de } \\
\text { espigas por } \\
\text { planta }\end{array}$ & $\begin{array}{c}\text { Número de } \\
\text { grãos por } \\
\text { espiga }\end{array}$ & $\begin{array}{c}\text { Massa de } \\
1000 \text { grãos } \\
(\mathrm{g})\end{array}$ & $\begin{array}{c}\text { Produtividade } \\
\left(\mathrm{Kg} \mathrm{ha}^{-1}\right)\end{array}$ \\
\hline PP & $0,94 \mathrm{a}$ & $528,1 \mathrm{a}$ & $290,02 \mathrm{a}$ & $10920 \mathrm{a}$ \\
PC & $0,98 \mathrm{a}$ & $476,7 \mathrm{a}$ & $320,95 \mathrm{a}$ & $10800 \mathrm{a}$ \\
\hline
\end{tabular}

Médias seguidas de letras iguais na coluna não diferem estatisticamente entre si pelo teste $t$ de Student a $5 \%$ de probabilidade. 


\section{CONCLUSÕES}

Com base nos resultados obtidos pode-se concluir que:

a) A RSP não restringiu o crescimento radicular do milho;

b) Nos dois sistemas de manejo, $90 \%$ das raízes se concentraram nos primeiros 20 cm de profundidade.

c) Não houve diferença significativa de produtividade do milho sob os manejos plantio direto e preparo convencional.

\section{REFERÊNCIAS BIBLIOGRÁFICAS}

AGUiAR E SILVA, M. A.; AZEVEDO, L. P.; SAAD, J. C. C.; MICHELS, R. N. Propriedades físico-hídricas, desenvolvimento radicular e produtividade da soja em dois tipos de manejos de solo. Irriga, Botucatu, v. 17, n. 3, p. 387-396, 2012.

ALBUQUERQUE, P. E. P.; RESENDE, M. Cultivo do milho. Manejo da irrigação. Sete Lagoas: Embrapa Milho e Sorgo, Sete Lagoas, 2002. (Comunicado Técnico, 47).

BARBER, S. A.; MACKEY, A.D.; KUCHENBUCH, R. O.; BARRACLOUGH, S. Effect of soil temperature and water on maize root growth. Plant and Soil, Dordrecht, v. 111, p. 267-269, 1988.

BERGAMIM, A. C.; VITORINO, C. T.; FRANCHINI, J. C. SOUZA, M. A.; SOUZA, F. R. Compactação em um lotossolo vermelho distraférrico e suas relações com o crescimento radicular do milho. Revista Brasileira de Ciência do Solo, Viçosa, v. 34, n. 3, p. 681-691, 2010.

BEROLINI, E. V.; GAMERO, C.A.; BENEZ, S. H. Desempenho da cultura do milho em diferentes manejos do solo sobre cobertura vegetal de nabiça (Raphanus raphanistrum L.). Engenharia agrícola, Jaboticabal, v. 21, n. 1, p. 34-49, 2006.

BESCANSA, P.; IMAZ, M. J.; VIRTO, I.; ENRIQUE, A.; HOOGMOED, W. B. Soil water retention as affected by tillage and residue management in semiarid Spain. Soil and Tillage Research, Amsterdam, v. 87, p. 19-27, 2006.

BORTOLUZZI, E. C.; SILVA, V. R.; PETRY, C.; CECCHETTI, D. Porosidade e retenção de água em um argissolo sob manejos convencionais e direto submetido a compressões unidimensionais. Revista Brasileira de Ciencia do Solo, Viçosa, v. 32, n. 4, p. 1447-1457, 2008.

CARVAlHO, M. A. C.; SORATTO, R. P.; ATHAYDE, M. L. F.; ARF, O.; SÁ, M. E. Produtividade do milho em sucessão a adubos verdes no sistema de plantio direto e convencional. Pesquisa Agropecuária Brasileira, Brasília, v. 39, n. 1, p. 47-53, 2004. 
CASTRO, O. M.; VIEIRA, S. R.; SIQUEIRA, G. M. Atributos físico-hídricos de um Latossolo Vermelho eutroférrico sob diferentes sistemas de manejo. Bragantia, Campinas, v. 69, n. 2, p. 433-443, 2010.

COSTA, F. S.; ALBUQUERQUE, J. A.; BAYER, C.; FONTOURA, S. M. V.; WOBETO, C. Propriedades físicas de um Latossolo Bruno afetadas pelos sistemas plantio direto e preparo convencional. Revista Brasileira de Ciências do Solo, Viçosa, MG, v. 27, p. 527-535, 2003.

COSTA, E. A.; GOEDERT, W. J.; SOUSA, D. M. G. Qualidade de solo submetido a sistemas de cultivo com preparo convencional e plantio direto. Pesquisa Agropecuária Brasileira, Brasília, DF, v. 41, n. 7, p. 1185-1191, 2006.

CUNHA, E. Q.; STONE, L. F.; MOREIRA, J. A. A.; FERREIRA, E. P. B.; DIDONET, A. D.; LEANDRO, W. M. Sistemas de preparo do solo e culturas de cobertura na produção orgânica de feijão e milho. I - Atributos físicos do solo. Revista Brasileira de Ciência do Solo, Viçosa, MG, v. 35, p. 589-602, 2011.

DALMAGO, G. A.; BERGAMASCHI, H.; BERGONCI, J. I.; KRÜGER, C. A. M. B.; COMIRAN, F.; HECKLER, B. M. M. Retenção e disponibilidade de água às plantas, em solo sob plantio direto e preparo convencional. Revista Brasileira de Engenharia Agrícola e Ambiental, Campina Grande, v. 13, p. 855-864, 2009. Suplemento.

DOURADO NETO, D., LIER, Q. J. V.; BOTREL, T. A., LIBARDI, P. L. Programa para confecção da curva característica de retenção de água no solo utilizando o modelo de Genuchten. Engenharia Agrícola, Jaboticabal, v. 1, n. 2, p. 94-101, 1990.

EMBRAPA. Sistema brasileiro de classificação de solos. 2. ed. Brasília: Embrapa, 2006. 306 p.

FREDDI, O. S.; CARVALHO, M. P.; JÚNIOR, V. V.; CARVALHO, G. J. Produtividade do milho relacionada com a resistência mecânica à penetração do solo sob preparo convencional. Engenharia Agrícola, Jaboticabal, v. 26, n. 1, p. 113-121, 2006.

HILL, R. L. Long term conventional and no-tillage effects on selected soil physical properties. Soil Science Society American Journal, Madison, v. 54, p. 161-166, 1990.

LANÇAS, K. P.; SANTOS FILHO, C. A. Penetrômetro hidráulico-eletrônico equipado com DGPS para avaliação da compactação do solo. La Plata: Editorial de la U.N.L.P, 1998.

LOPES, J. P.; MACHADO, E. C.; DEUBER, R.; MACHADO, R. S. Análise de crescimento e trocas gasosas na cultura de milho em plantio direto e convencional, Bragantia, Campinas, v. 68, n. 4, p. 839-848, 2009.

MARQUES, S. R.; WEILL, M. A. M.; SILVA, L. F. S. Qualidade física de um latossolo vermelho, perdas por erosão e desenvolvimento do milho em dois sistemas de manejo. Ciência e Agrotecnologia, Lavras, v. 34, n. 4, p. 967-974, 2010. 
MORET, D.; ARRÚE, J. L. Dynamics of soil hydraulic properties during fallow as affected by tillage. Soil and Tillage Research, Amsterdam, v. 96, p. 103-113, 2007.

PIRES, L. F., ROSA, J. A.; TIMM, L. C. Comparação de métodos de medida da densidade do solo. Acta Scientarium Agronomy, Maringá, v. 33, n. 1, p. 161-170, 2011.

REINERT, D. J.; ALBUQUERQUE, J. A.; REICHERT, J. M.; AITA, C.; ANDRADA, M. M. C. Limites críticos de densidade do solo para o crescimento de raízes de plantas de cobertura em argissolo vermelho. Revista Brasileira de Ciência do Solo, Viçosa, v. 32, p. 1805-1816, 2008.

SHUKLA, M. K.; LAL, R.; EBINGER, M. Tillage effects on physical and hydrological properties of a typic argioquoll in Central Ohio. Soil Science, Philadelphia, v. 168, n.11, p. 802$811,2003$.

SILVA, M. A. S.; MAFRA, A. L.; ALBUQUERQUE, J. A.; BAYER C., MIELNICZUK, J. Atributos físicos do solo relacionados ao armazenamento de água em um Argissolo Vermelho sob diferentes sistemas de preparo. Ciência Rural, Santa Maria, v. 35, n. 3, p. 544-552, 2005.

SILVEIRA NETO, A. N.; SILVEIRA, P. M.; STONE, L. F.; OLIVEIRA, L. F. C. Efeito de manejo e rotação de culturas em atributos físicos do solo. Pesquisa Agropecuária Tropical, Goiânia, v. 36, n.1, p. 29-35, 2006.

SOANE, B. D.; BALL, B.C. Review of management and conduct of long-term tillage studies with special reference to a 25 years experiment on barley in Scotland. Soil and Tillage Research, Amsterdam, v. 45, n. 1, p. 17-37, 1998.

TAVARES FILHO, J.; BARBOSA, G. M. C.; GUIMARÃES, M. F.; FONSECA, I. C. B. Resistência do solo à penetração e desenvolvimento do sistema radicular do milho (Zea maysL.) sob diferentes sistemas de manejo em um Latossolo Roxo. Revista Brasileira de Ciência do Solo, Campinas, v. 25, p. 725-730, 2001.

TENNANT, D. A test of a modified line intersect method of estimating root length. Journal of Ecology, Londres, v. 63, p. 995-1001, 1975.

VAN GENUCHTEN, M. A closed-from equation for predicting the conductivity of unsaturated soils. Soil Science Society of American Journal, Madison, v. 44, p. 892-898, 1980.

VITA, P.; PAOLO, E. D.; FECONDO, G.; FONZO, N. D.; PISANTE, M. No-tillage and convencional tillage effects on durun wheat yield, grain quality and soil moisture content in southern Italy. Soil and Tillage Research, Amsterdam, v. 92, p. 69-78, 2007. 